\title{
Absence of lung fibrosis after a single pulmonary delivery of lipid nanocapsules in rats
}

\author{
This article was published in the following Dove Press journal: \\ International Journal of Nanomedicine \\ 8 November 2017 \\ Number of times this article has been viewed
}

José Hureaux ${ }^{1,2}$

Franck Lacœuille ${ }^{3,4}$

Frédéric Lagarce ${ }^{1,5}$

Marie-Christine Rousselet ${ }^{6}$

Aurélien Contini ${ }^{3,4}$

Patrick Saulnier ${ }^{1,7}$

Jean-Pierre Benoit ${ }^{1,5}$

Thierry Urban ${ }^{1,2}$

'Unité Micro et Nanomédecines Biomimétiques (MINT), Université d'Angers, INSERM 1066, CNRS 602I, Université Bretagne Loire, ${ }^{2}$ Université d'Angers, CHU, Pôle Hippocrate, Service de Pneumologie, ${ }^{3}$ Université d'Angers, CHU, Pôle Signal Image Stérilisation, Service de Médecine nucléaire, ${ }^{4} \mathrm{CRCINA}$, Université Nantes Université Angers, ${ }^{5}$ Université d'Angers, $\mathrm{CHU}$, Pôle Hippocrate, Pharmacie, 'Université d'Angers, $\mathrm{CHU}$, Pôle de Biologie-Pathologie, Département de Cytologie et d'Histologie Pathologique, 'Université d'Angers, CHU, Service la Recherche Clinique et Innovation, Angers, France

Correspondence: José Hureaux $\mathrm{CHU}$, Pôle Hippocrate, Service de Pneumologie, 4 rue Larrey, 49933 Angers, France

$\mathrm{Tel}+33241353678$

Fax +33 241354974

Email jose.hureaux@chu-angers.fr

Abstract: Lipid nanocapsules (LNCs) are potential drug carriers for pulmonary delivery since they can be nebulized without any structural or functional changes, and the aerosols produced are highly compatible with pulmonary drug delivery in human beings. The alveolar surface tension, in vitro cytotoxicity, biodistribution and pulmonary toxicity in rats of a single endotracheal spray of LNCs or paclitaxel-loaded LNCs were studied. In vitro cytotoxicity of LNCs after a spray remained unchanged. Biodistribution study showed a homogeneous repartition in the lungs in rats with an improvement in lung retention of the radiolabeled tracer loaded in LNCs compared to the absence of LNCs with a lung half-time of $8.8 \pm 0.7$ hours. Bronchoalveolar fluid analysis revealed transient 7-day alveolar inflammation, reaching a maximum between days 2 and 4 , characterized by a peak of granulocytes at day 1 followed by a peak of lymphocytes at day 3 . Alveolar protein levels were increased at days 3 and 7. Acute inflammation was increased with paclitaxel-loaded LNCs in comparison with blank LNCs but dropped out at day 7. No histological pulmonary lesion was observed at day 60 . LNCs lowered surface tension to a greater degree than Curosurf $^{\circledR}$ in a physicochemical model of the pulmonary alveolus. A single pulmonary delivery of LNCs induces a short-term alveolar inflammation with no residual lesions in rats at day 60 . These data permit to start the study of LNCs in surfactant replacement therapy.

Keywords: lipid nanocapsules, pulmonary drug delivery, biodistribution, toxicity, paclitaxel

\section{Introduction}

Lipid nanocapsules (LNCs) are nanometric vectors that can be used to dissolve lipophilic drugs without the need of organic solvents or excipients known to have a recognized effect. ${ }^{1}$ They are versatile nano-sized drug carriers able to solubilize highly lipophilic drugs and to generate aerosols as paclitaxel (PTX) or fluticasone propionate. ${ }^{2,3}$ The produced aerosols are compatible with pulmonary drug delivery in human beings, with an aerosol mass median aerodynamic diameter equal to $2.7 \pm 0.1 \mu \mathrm{m}$ and a fine particle fraction (between 1.0 and $5.0 \mu \mathrm{m}$ ) of $81.5 \% \pm 3.1 \%{ }^{4}$

Pulmonary drug delivery presents a number of advantages to treat chronic lung diseases such as asthma, chronic obstructive pulmonary disease or cystic fibrosis, or acute diseases such as hyaline membrane disease in preterm neonates. ${ }^{5-8}$ Aerosolized anticancer drugs have potential interests to treat lung adenocarcinoma or lung metastases. ${ }^{9}$ The main advantages are direct access to the zones to be treated, allowing a reduction in the doses administered to the patient and consequently a reduction in systemic adverse effects. In addition, the pulmonary route has new interest in newborns, because it could reduce the potential interactions with the intestinal microbiota and could avoid interference with the immune development or the gut-brain axis. ${ }^{10-13}$

Preclinical toxicological data on LNCs obtained after intravenous administration in mice have demonstrated the good safety of these nanocarriers. ${ }^{14,15}$ On the contrary, 
published data on some pulmonary drug delivery systems have shown acute toxicity in mice. In fact, surface hydrophobicity of nanoparticles from 50 to $150 \mathrm{~nm}$ was characterized by hydrophobic interaction chromatography (HIC). The acute lung inflammation was quantified after pulmonary administration to mice. The correlation between nanomaterial HIC index and acute lung inflammation was determined for LNCs, polyvinyl acetate and polystyrene nanoparticles. This study showed that LNCs have a low HIC index and induce little inflammation unlike polyvinyl acetate and polystyrene nanoparticles characterized by high HIC index and increase acute alveolar toxicity. ${ }^{16}$ In another study, the relationships between nanoparticle hydrophobicity, inflammatory outcomes and the metabolic fingerprint in bronchoalveolar fluid from mice exposed to various nanoparticles were studied following a single-dose intratracheal administration. Results confirm that particles with high surface hydrophobicity were proinflammatory and that adenosine monophosphate (AMP) concentration in bronchoalveolar fluid was correlated with neutrophilia and nanoparticle surface hydrophobicity. ${ }^{17}$ Grabowski et al, ${ }^{18}$ in a model of human respiratory alveolar epithelium cell culture, have clearly demonstrated that the inflammation and cell damage induced by these vectors are correlated with the surface charge and the nature of the nanoparticle core.

The purpose of this study was to determine the potential toxicity of a single endotracheal spray of LNCs in rats. We studied in vitro cytotoxicity of blank and PTX-loaded LNCs (PTX-LNCs), biodistribution and acute and middleterm pulmonary toxicities of blank and PTX-LNCs in rats after a single endotracheal spray. We also studied the alveolar surface tension of LNCs on a physicochemical model of the pulmonary alveolus.

\section{Materials and methods Materials}

Lipoid $^{\circledR}$ P75-3 (genetically modified organism-free soybean lecithin containing $69 \%$ of phosphatidylcholine), Captex ${ }^{\circledR}$ 8000 (glyceryl tricaprylate), Labrafac ${ }^{\circledR}$ CC (caprylic-capric acid) and Kolliphor ${ }^{\circledR}$ HS15 (polyethyleneglycol ester of 12-hydroxystearic acid and polyethylene glycol) were obtained from Lipoid GmbH (Ludwigshafen, Germany), Abitec Corp. (Columbus, OH, USA), Gattefosse SA (St-Priest, France) and BASF (Ludwigshafen, Germany), respectively. PTX powder and commercial Taxol ${ }^{\circledR} 6 \mathrm{mg} / \mathrm{mL}$ were provided by LC Laboratories (Woburn, MA, USA) and BristolMyers Squibb (Rueil-Malmaison, France), respectively. Distilled water was obtained from Cooper (Melun, France).
Sodium chloride $(\mathrm{NaCl})$ was obtained from Prolabo VWR International (Fontenay-sous-Bois, France). Sterile saline serum was supplied by Aguettant (Lyon, France). Dichloromethane was supplied by Sigma-Aldrich Co. (St Louis, MO, USA). Phosphate-buffered saline (PBS) was obtained from Lonza (Verviers, Belgium). Ministar ${ }^{\circledR} 0.20 \mu \mathrm{m}$ highflow filters from Sartorius AG (Goettingen, Germany) were used. Cryo.S cryotubes were purchased from Greiner Bio-One (Frickenhausen, Germany). About 4\% phosphate-buffered formalin was obtained from Labonord (Templemars, France). ${ }^{99 \mathrm{~m}} \mathrm{Tc}$-pertechnetate $\left.{ }^{{ }^{99} \mathrm{~m}} \mathrm{TcO}_{4}{ }^{-}\right)$was obtained by saline elution of a ${ }^{99} \mathrm{Mo} /{ }^{99 m} \mathrm{Tc}$ generator (IBA, Paris, France). Excipients for the formulation of the ${ }^{99 \mathrm{~m}} \mathrm{Tc}$-super six sulfur lipophilic complex were obtained from Chemical Engineering and Molecules for Life Sciences Platform (Rennes, France). Curosurf ${ }^{\circledR}$ was obtained from our academic pharmacy.

\section{LNCs}

\section{Preclinical batches of LNCs}

The study was performed on LNCs having a mean diameter of $55 \mathrm{~nm}$ and prepared according to a scaled-up protocol that was compliant with the original process and allowed the production of standard batches for in vivo studies. ${ }^{1,4,19}$ Briefly, Captex 8000, Lipoid S75-3, Kolliphor HS15, NaCl and water (12 g, $672 \mathrm{mg}, 10 \mathrm{~g}, 733 \mathrm{mg}$ and $18 \mathrm{~g}$, respectively) were mixed and heated to $90^{\circ} \mathrm{C}$ under magnetic stirring. Three cycles of progressive heating and cooling between $90^{\circ} \mathrm{C}$ and $70^{\circ} \mathrm{C}$ were then carried out. Thermal exchanges were optimized by bathing in water at $95^{\circ} \mathrm{C}$ and at room temperature. This step was followed by an irreversible shock, induced by dilution with $112 \mathrm{~mL}$ of $0^{\circ} \mathrm{C}$ deionized water added to the mixture at a temperature of $78^{\circ} \mathrm{C}$. Magnetic stirring was applied to the LNCs suspension for 5 minutes at room temperature, and molar sodium hydroxide and $\mathrm{NaCl}$ were added $(50 \mu \mathrm{L}$ and $110 \mathrm{mg}$, respectively). The dispersion was filtered through a $0.20 \mu \mathrm{m}$ Ministar filter into a sterile CRYO.S cryotube. For the formulation of PTX-LNCs, 1.8\% w/w of PTX powder was first solubilized in Captex 8000 under magnetic stirring and heated at $50^{\circ} \mathrm{C}$ for 30 minutes. The procedure described earlier was then applied to this mixture. CRYO.S cryotubes, previously filled with LNCs dispersion, were frozen in liquid nitrogen. Cryotubes were thawed at room temperature for 30 minutes before use. This procedure allowed to obtain a suspension with a concentration of $0.181 \mathrm{mg} / \mathrm{mL}$ of PTX.

\section{Batches of radiolabeled LNCs}

LNCs loaded with technetium-99m ( ${ }^{99 m} \mathrm{Tc}-\mathrm{SSS}-\mathrm{LNCs}$ ) were obtained by means of a two-step procedure. The first step 
consisted of preparation of a ${ }^{99 \mathrm{~m}} \mathrm{Tc}-\mathrm{SSS}$ complex according to a previously described method. ${ }^{20}$ Briefly, the ${ }^{188} \mathrm{Re}-\mathrm{SSS}$ complex was obtained by the reaction of the ligand sodium dithiobenzoate (Chemical Engineering and Molecules for Life Sciences Platform) with a freeze-dried formulation kit containing $30 \mathrm{mg}$ of sodium gluconate, $30 \mathrm{mg}$ of ascorbic acid, $40 \mathrm{mg}$ of potassium oxalate and $4 \mathrm{mg}$ of $\mathrm{SnCl}_{2} \cdot 2 \mathrm{H}_{2} \mathrm{O}$ reconstituted in $0.5 \mathrm{~mL}$ of normal saline. About $1,110 \mathrm{MBq}$ of ${ }^{99 \mathrm{~m}} \mathrm{Tc}$-pertechnetate $\left({ }^{99 \mathrm{~m}} \mathrm{TcO}_{4}{ }^{-}\right.$in $\left.0.5 \mathrm{~mL}\right)$ was added, and the solution was mixed for 15 minutes at room temperature. About $20 \mathrm{mg}$ of sodium dithiobenzoate (in $0.5 \mathrm{~mL}, \mathrm{pH}=7$ ) was then added before heating at $100^{\circ} \mathrm{C}$ for 30 minutes, resulting in the formation of the ${ }^{99 \mathrm{~m}} \mathrm{Tc}-\mathrm{SSS}$ lipophilic complex. The second step consisted of encapsulation of the newly formed ${ }^{99 m}$ Tc-SSS complexes in the lipophilic core of the nanocapsules. For this purpose, LNCs were prepared according to the phase inversion process described earlier.

\section{Characterization of LNCs}

Size distribution, polydispersity index and zeta potential measurements of LNCs dispersions were characterized by photon correlation spectroscopy using a Malvern Zetasizer ${ }^{\circledR}$, Nano Series DTS 1060 (Malvern Instruments, Malvern, UK). To determine the drug payload, PTX-LNCs dispersions were filtered through $0.22 \mu \mathrm{m}$ Ministar high-flow filters. PTX concentrations and encapsulation efficiency were measured in the supernatant by high-performance liquid chromatography in triplicate experiments according to a previously described protocol. ${ }^{14}$ The same experiments were performed with LNCs dispersions after formation of an aerosol.

\section{Formation of LNCs aerosols}

Pulmonary nebulization of LNCs in rodents was generated by means of an endotracheal spray produced by a MicroSprayer ${ }^{\circledR}$ Aerosolizer-Model IA-1C-R (Penn-Century, Inc., Wyndmoor, PA, USA) according to a previously published method. ${ }^{21}$ Briefly, after isoflurane-induced anesthesia, rats were suspended by their upper incisors. The tip of the MicroSprayer Aerosolizer was introduced into the animal's trachea using a pediatric laryngoscope. Aerosol deliveries were performed under a fume hood to avoid exposure of the operator. The aerosol was collected in a CRYO.S cryotube for analysis of the LNCs after passage in the MicroSprayer.

\section{In vitro cytotoxicity study}

The in vitro cytotoxicity of thawed LNCs, "sprayed" and thawed LNCs, thawed PTX-LNCs and sprayed and thawed PTX-LNCs on NCI-H460 human lung cancer cells was determined using a growth inhibition assay. A NCI-H460 human, large cell lung carcinoma cell line was obtained from the American Type Culture Collection (ATCC, Manassas, VA, USA). Cells were cultured in RPMI 1640 medium containing glutamine (Lonza), 10 mM HEPES (4-(2-hydroxyethyl)-1piperazineethanesulfonic acid) (Sigma-Aldrich Co.), $1 \mathrm{mM}$ sodium pyruvate (Lonza), $1.5 \mathrm{~g} / \mathrm{L}$ sodium bicarbonate (Cambrex Biosciences, Verviers, Belgium), 10\% fetal bovine serum (Lonza), $50 \mathrm{U} / \mathrm{mL}$ penicillin and $50 \mathrm{mg} / \mathrm{mL}$ streptomycin (Sigma-Aldrich Co.). Cells were routinely maintained at $37^{\circ} \mathrm{C}$ in a humidified atmosphere of $5 \% \mathrm{CO}_{2}$ in air. The culture medium was replaced every 2 or 3 days, and the cells were subcultured weekly using $0.25 \%$ trypsin -1 mM EDTA (Sigma-Aldrich Co.). Tumor cells were seeded in 24-well plates at 50,000 cells/well. All the assays were performed with exponentially growing cultures. A drug-containing medium was added after 48 hours. A dose range from $10^{-3}$ to $100 \mathrm{nM}$ PTX-LNCs or LNCs formulations was tested for each sample. Cytotoxicity was assessed after 2 days of exposure by adding $80 \mu \mathrm{L}$ of CellTiter $96^{\circledR} \mathrm{Aq}_{\text {ueous }}$ One Solution Reagent (Promega Corporation, Fitchburg, WI, USA) to each well according to the manufacturer's instructions. ${ }^{22,23}$ After 4 hours of culture, cell viability was determined by measuring the absorbance at $492 \mathrm{~nm}$ using a Multiskan Ascent microplate reader (Thermo Fisher Scientific, Waltham, MA, USA). As LNCs dispersions are not translucent, the absorbance of wells containing the cells was subtracted from the absorbance of wells containing culture medium alone for each point. The half-maximal inhibitory concentration $\left(\mathrm{IC}_{50}\right)$ of the drug was calculated. Three independent experiments were performed in triplicate.

\section{Animal studies}

Experiments were performed in 180 female, 8-10-week-old Sprague-Dawley rats weighing 200-300 g (Janvier Labs, Le Genest Saint Isle, France) housed in the Angers University Hospital animal facility. Animals were provided with food and drinking water ad libitum according to a regular 12-hour day/night cycle. After 1 week of acclimatization, animals were randomized to experimental groups. Following randomization, animals were observed and weighed daily. Weight loss, the appearance of the fur, respiratory rate, behavior and responses to normal stimuli were evaluated daily according to the toxicity scale described elsewhere. ${ }^{14}$ For each animal, a single daily endotracheal spray of $200 \mu \mathrm{L}$ was administered during brief isoflurane anesthesia according to a validated protocol. ${ }^{21}$ This volume corresponds to a surface area dose of $\sim 2,650 \mathrm{~cm}^{2}$ per animal. The research complied with 
the European Community guidelines for the protection of animals used for scientific purposes. The experimental protocol was approved by the Pays de la Loire ethics committee on animal experiments (number 2011.9), and studies were conducted in compliance with French legislation.

\section{Biodistribution study}

Six female Sprague Dawley rats were housed in individual metabolism cages for the collection of urine and feces. For the biodistribution studies, $15 \mathrm{MBq}$ of the LNCs- ${ }^{99 \mathrm{~m}} \mathrm{Tc}-\mathrm{SSS}$ suspension $(n=4)$ or the ${ }^{99 m}$ Tc-pertechnetate solution $\left({ }^{99} \mathrm{TcO}_{4}{ }^{-} \mathrm{Na}^{+}\right)$as control $(\mathrm{n}=2)$ was administered by the endotracheal spray technique $(15 \mathrm{MBq} / 200 \mu \mathrm{L})$ in xylazine- and isoflurane-anesthetized healthy Wistar rats. Static acquisitions were obtained at the times 10 minutes, 1 hour, 3 hours and 22 hours using a SOPHA DSX $\gamma$-camera (Sopha Medical Vision, Buc, France) dedicated to animal studies. A scout view was acquired on a GE LightSpeed system (GE Healthcare UK Ltd, Little Chalfont, UK) and fused with the planar scintigraphy of the same animal for anatomical localization of

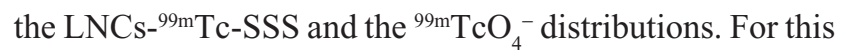
purpose, the acquired images were analyzed and processed on a Xeleris 2 workstation (GE Healthcare). Regions of interest (ROIs) were drawn manually on various organs (lungs, liver, stomach, spleen, trachea) on the planar images. Time-activity curves for the LNCs- ${ }^{99 \mathrm{~m}} \mathrm{Tc}-\mathrm{SSS}$ - and the ${ }^{99 \mathrm{~m}} \mathrm{TcO}_{4}^{-}$controlinjected rats were obtained by plotting the ROIs on the images for the various acquisition times. The activity in the ROI was expressed as a percentage of the injected dose. To compare the lung clearance $(\mathrm{Cl})$ kinetics of the LNCs- ${ }^{99 \mathrm{~m}}$ Tc-SSS and the ${ }^{99} \mathrm{TcO}_{4}^{-}$controls, several pharmacokinetic parameters such as lungs' half-life $\left(\mathrm{T}_{1 / 2}\right)$, mean residence time (MRT) and $\mathrm{Cl}$ were calculated using a non-compartmental model for the analysis of the pharmacokinetics data (Kinetica 5.1 software; Thermo Fisher Scientific).

\section{Lung wet/dry weight and lung/body weight ratios and histological examination}

Exploratory analysis of lung wet/dry weight and lung/body weight ratios was designed to determine the duration and intensity of any pulmonary inflammation induced by the various aerosols. ${ }^{24}$ Animals were randomized in 19 groups of six rats: one control group receiving no spray, six groups receiving one saline serum spray, six groups receiving one blank LNCs spray and six groups receiving one PTX-LNCs spray. A batch of animals from each group was sacrificed on days 1 (24 hours after endotracheal spray), 2, 4, 7, 21 and 60. Each animal was weighed before sacrifice, and the fresh weight of the lungs was determined after sacrifice. Necropsy (thorax + abdomen + pelvis) was performed on each animal at the time of sacrifice. Light microscopy histological examination of the lungs was performed on the animals of the three groups sacrificed on day 60. Lungs were fixed in 50\% formalin for histological examination. About $5 \mu \mathrm{m}$ paraffin-embedded and hematoxylineosin-saffron-stained sections were analyzed according to a previously published score. ${ }^{14}$ This score assessed lung inflammation in four lung sectors: peribronchiolar, perivascular, interstitial and alveolar. For each sector, the histopathological aspect was scored on a scale of 0 (no change: normal aspect), 1 (mild inflammation: dispersed mononuclear leukocytes), 2 (moderate inflammation: presence of one to three nodules of mononuclear leukocytes) and 3 (severe inflammation: more than three nodules of mononuclear leukocytes). The final score was the sum of the highest scores observed in each sector of the lungs. The researchers who examined the slides were blinded to the treatments received by the rats. A total of 114 animals were included in this study.

\section{Bronchoalveolar lavage (BAL) examination}

Animals were randomized to 10 groups of six rats: one control group receiving no spray, three groups receiving one saline serum spray, three groups receiving one blank LNCs spray and three groups receiving one PTX-LNCs spray. BAL was performed on a batch of animals from each group on days 1 ( 24 hours after endotracheal spray), 3 and 7. After sacrifice by inhalation of $5 \% \mathrm{CO}_{2}, \mathrm{BAL}$ was performed on both lungs in the following way: the trachea was surgically exposed and incised transversely to introduce a metal cannula with a watertight seal. Two aliquots of $7.5 \mathrm{~mL}$ of PBS were then injected. The fluid was re-aspirated with the syringe. BAL fluid was then centrifuged at $1,500 \mathrm{rpm}$ at $4^{\circ} \mathrm{C}$, and the pellet was recovered and suspended in $250 \mu \mathrm{L}$ of PBS. Global alveolar cellularity was determined by counting on a Malassez cell. The differential cell count was determined after centrifugation and smearing on a slide with a Cytospin 4 and Hematoxylin -Eosin -Saffron (HES) staining. At least 100 cells were counted to determine the proportion of macrophages, neutrophils, eosinophils and lymphocytes. The lipid index of foamy macrophages was calculated according to Hopkins et al. ${ }^{25}$ Briefly, Oil red O staining was performed in BAL cells. The red vacuoles of 100 consecutive macrophages were scored from 0 to 4 ( 0 : absence of staining, 1 : presence of one to three intracellular distinct lipid droplets, 2: more than three distinct lipid droplets, 3 : multiple confluent droplets with visible nucleus, 4: complete opacifications of the cytoplasm with obscuration of the nucleus). The lipid 
index was computed as the summation for all scores. The researchers who examined the slides were blinded to the treatments received by the 60 rats. The supernatant was collected for the assay of total alveolar protein by the BCA protein assay kit (Pierce Biotechnology, Rockford, IL, USA) according to the manufacturer's instructions.

\section{Study of alveolar surface tension}

Alveolar surface tension was studied by means of a pendantdrop tensiometer (Tracker; IT Concept, Longessaigne, France) based on the captive bubble model. ${ }^{26-28}$ The $5 \mu \mathrm{L}$ bubble was immersed in a saline bath at $37^{\circ} \mathrm{C}$. Surface tension was measured under static conditions for 3 minutes to determine the equilibrium surface tension and the time required to achieve this equilibrium for four solutions: saline; $50 \mu \mathrm{g} / \mathrm{mL}$ Curosurf; $50 \mu \mathrm{g} / \mathrm{mL}$ Kolliphor HS15 or LNCs at a concentration equivalent to $50 \mu \mathrm{g} / \mathrm{mL}$ of Kolliphor HS15. Equilibrium adsorption data are expressed as time, and minimum surface tension is expressed in $\mathrm{mN} / \mathrm{m}$. The results of three independent experiments are presented (mean $\pm \mathrm{SD}$ ).

\section{Statistical analysis}

Results are expressed as mean \pm SD. A Kruskal-Wallis test was used to determine statistical significance, completed by a Mann-Whitney $U$-test. In every case, $p<0.05$ was considered to be significant. SPSS version 19 software (IBM Corporation, Armonk, NY, USA) was used for statistical analysis.

\section{Results}

\section{Characteristics of batches of LNCs}

The structural characteristics of blank LNCs and PTX-LNCs after thawing and passage in the MicroSprayer Aerosolizer are presented in Table 1. The mean particle sizes of thawed blank LNCs, thawed and sprayed blank LNCs, thawed PTXLNCs, thawed and sprayed PTX-LNCs and radiolabeled

Table I Characterization of LNCs batches

\begin{tabular}{lllll}
\hline $\begin{array}{l}\text { Formulation } \\
\text { group }\end{array}$ & $\begin{array}{l}\text { Mean } \\
\text { particle } \\
\text { size }(\mathbf{n m})\end{array}$ & $\begin{array}{l}\text { Polydispersity } \\
\text { index }\end{array}$ & $\begin{array}{l}\text { Zeta } \\
\text { potential } \\
(\mathbf{m V})\end{array}$ & IC $_{50}(\mathbf{n M})$ \\
\hline $\begin{array}{l}\text { Thawed blank LNCs } \\
65.5 \pm 0.2\end{array}$ & $0.039 \pm 0.005$ & $-6.9 \pm 0.3$ & 2.1 \\
$\begin{array}{l}\text { Thawed and } \\
\text { sprayed blank LNCs }\end{array}$ & $65.6 \pm 2.5$ & $0.126 \pm 0.008$ & $-8.4 \pm 0.2$ & 2.1 \\
Thawed PTX-LNCs & $65.2 \pm 0.8$ & $0.039 \pm 0.005$ & $-7.9 \pm 0.3$ & 2.4 \\
$\begin{array}{l}\text { Thawed and } \\
\text { sprayed PTX-LNCs }\end{array}$ & $65.0 \pm 0.4$ & $0.107 \pm 0.007$ & $-7.8 \pm 0.9$ & 2.3 \\
Radiolabeled LNCs & $55.9 \pm 0.6$ & $0.038 \pm 0.008$ & $-9.3 \pm 0.6$ & - \\
\hline
\end{tabular}

Note: Experiments were performed in triplicate.

Abbreviations: $I C_{50}$, half-maximal inhibitory concentration; LNCs, lipid nanocapsule; PTX, paclitaxel; PTX-LNCs, PTX-loaded LNCs.
LNCs were 65.5, 65.6, 65.2, 65.0 and 55.9, respectively. The polydispersity indexes of thawed blank LNCs, thawed PTX-LNCs and radiolabeled LNCs were 0.039, 0.039 and 0.038 , respectively. These indexes were increased to 0.126 and 0.107 after passage in the MicroSprayer Aerosolizer for thawed blank LNCs and thawed PTX-LNCs, respectively. The zeta potentials of the dispersions were found between -6.9 and $-9.3 \mathrm{mV}$. For drug-loaded nanocarriers, the PTX payload was equal to $1.6 \pm 0.1 \mathrm{mg} / \mathrm{mL}$ after thawing and remained unchanged after passage in the MicroSprayer Aerosolizer.

\section{In vitro cytotoxicity study}

The results of cytotoxicity assays are presented in Figure 1 and Table 1. The $\mathrm{IC}_{50}$ of PTX was $3.1 \mathrm{nM}$, as published elsewhere $(4.8 \mathrm{nM}){ }^{29}$ The $\mathrm{IC}_{50}$ values of thawed blank LNCs, thawed and sprayed blank LNCs, thawed PTX-LNCs and thawed and sprayed PTX-LNCs were 2.1, 2.1, 2.4 and $2.3 \mathrm{nM}$, respectively.

\section{Animal studies}

The endotracheal spray procedure did not induce any mortality. All animals resumed a normal behavior immediately after waking. No pathological respiratory or general signs were observed in the animals. The daily toxicity score was equal to 0 for each rat on each day. Weight gain was observed in all the animals after administration of the spray until the day of sacrifice, with no significant difference between the groups. In view of the concentration of the LNCs formulations, the administration of $200 \mu \mathrm{L}$ of spray corresponds to a mass dose

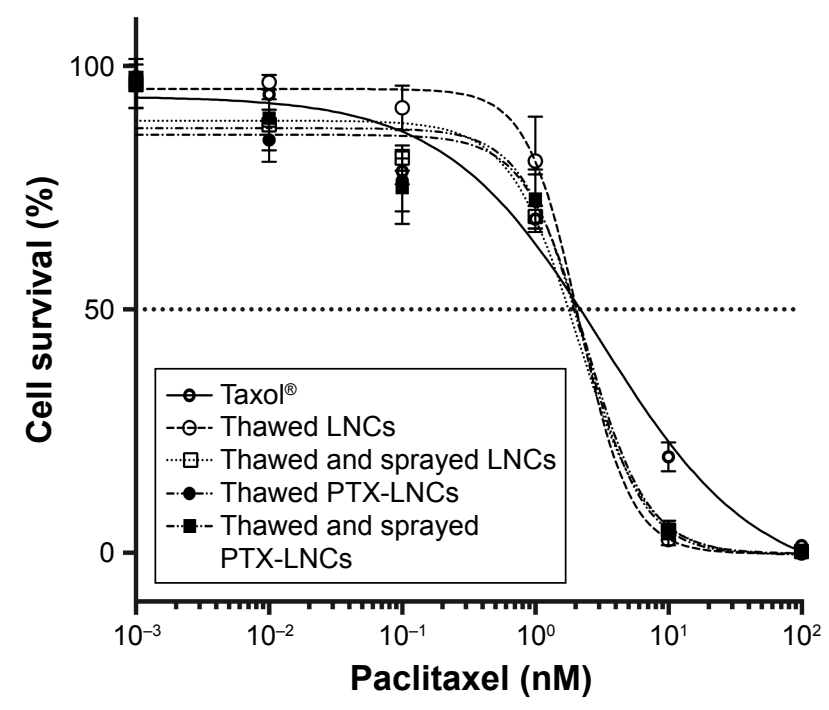

Figure I Growth inhibition assay of $\mathrm{Taxo}^{\circledR}$, thawed LNCs, thawed and sprayed LNCs, thawed PTX-LNCs and thawed and sprayed PTX-LNCs on $\mathrm{NCl}-\mathrm{H} 460$ cell growth.

Note: This result shows that the $\mathrm{IC}_{50}$ is equal.

Abbreviations: $\mathrm{IC}_{50}$, half-maximal inhibitory concentration; LNCs, lipid nanocapsule; PTX, paclitaxel; PTX-LNCs, PTX-loaded LNCs. 
of $\sim 36 \mu \mathrm{g}$ per animal and a surface area of about $\sim 2,650 \mathrm{~cm}^{2}$ for the two lungs.

\section{Biodistribution study}

Only a low level of the radioactivity deposition in the trachea $(6.08 \% \pm 1.14 \%$ and $11.15 \% \pm 2.99 \%$, respectively) was observed following the endotracheal administration of

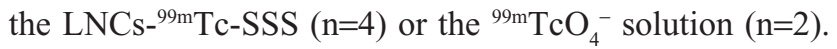
As expected, 10 minutes after the administration of the LNCs${ }^{99 \mathrm{~m}} \mathrm{Tc}-\mathrm{SSS}$ or the ${ }^{99} \mathrm{~m} \mathrm{TcO}_{4}^{-}$, the static planar scintigraphic acquisitions combined with scout scans revealed distribution of both tracers in the lungs. However, subsequent acquisitions (1, 3 and 22 hours post injection) showed dramatic changes between the distribution of the LNCs- ${ }^{99 m} \mathrm{Tc}-\mathrm{SSS}$ and the ${ }^{99} \mathrm{TcO}_{4}^{-}$(Figure 2A and B). Time-activity curves extracted from the scintigraphic acquisition provided details regarding tracer distribution kinetics following endotracheal administration (Figure 3). Lung $\mathrm{Cl}$ kinetics of LNCs- ${ }^{99 m} \mathrm{Tc}-\mathrm{SSS}$ appeared to be slow with a lung $\mathrm{T}_{1 / 2}$ of $8.8 \pm 0.7$ hours, an MRT of 12.9 \pm 0.9 hours and a $\mathrm{Cl}$ of $0.087 \pm 0.007 \mathrm{~h}^{-1}$ (Figure $3 \mathrm{~A}$ ), whereas the lung $\mathrm{Cl}$ of ${ }^{99 \mathrm{~m}} \mathrm{TcO}_{4}^{-}$was significantly faster with

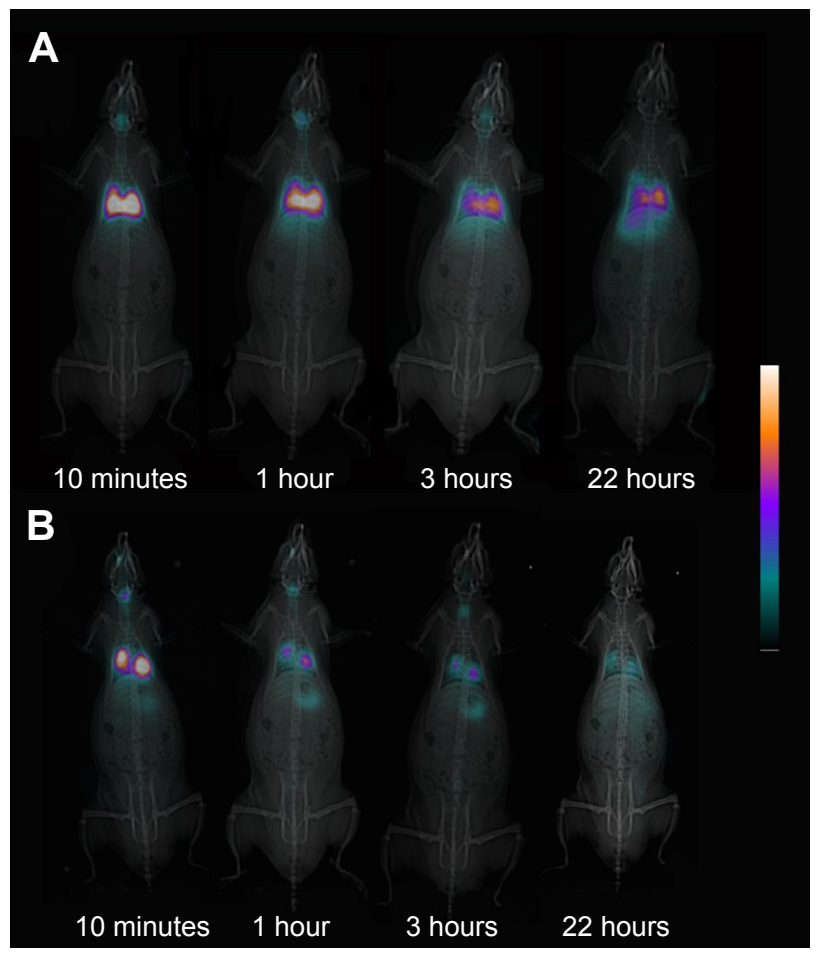

Figure 2 Scout view on a GE LightSpeed system fused with the planar scintigraphy of the same animal for the anatomical localization of the LNCs- ${ }^{99 m}$ Tc-SSS (A) and the ${ }^{99 \mathrm{~m}}$ Tc-pertechnetate distributions (B) at 10 minutes, I hour, 3 hours and 22 hours following the unique endotracheal spray technique administration.

Notes: The successive acquisitions showed the lung distribution of the LNCs- ${ }^{99 m}$ TcSSS (A) and a lung $\mathrm{Cl}$ significantly slowed compared to the control (B). The extrapulmonary distribution of the LNCs- ${ }^{99 \mathrm{~m} T \mathrm{~T}-\mathrm{SSS}}$ is considerably reduced compared to the control.

Abbreviations: $\mathrm{Cl}$, clearance; LNCs, lipid nanocapsule. a $\mathrm{T}_{1 / 2}=3.4 \pm 1.0$ hours $(p=0.0013)$, an MRT of $4.9 \pm 1.4$ hours ( $p=0.001)$ and $\mathrm{Cl}$ of $0.273 \pm 0.068 \mathrm{~h}^{-1}(p=0.0036$; Figure $3 \mathrm{~B})$. The lung $\mathrm{Cl}$ of the $\mathrm{LNCs}-{ }^{99 \mathrm{~m}} \mathrm{Tc}-\mathrm{SSS}$ was concomitant with an increase in radioactivity in the liver. In contrast, the stomach was the first elimination organ detected after the $\mathrm{Cl}$ of the ${ }^{99} \mathrm{TcO}_{4}^{-}$from the lungs.

\section{Animal's lung wet/dry weight and lung weight/body weight ratios}

The lung wet/dry weight ratios were not significantly different between the groups from day 1 to 60 (data not shown). The study of the animal's lung weight/body weight ratio is shown in Figure 4. This ratio was significantly higher in the blank NCL spray and PTX-LNCs spray groups by day 1 compared to the control group. This increased ratio reached a maximum between days 2 and 4 and returned to normal on day 7 and was comparable to that observed in the control group on days 21 and 60. By applying the rule of three Rs to animal experimentation, we therefore decreased the number of animal analyses by removing the day 21 and day 60 groups and by pooling the day 2 and day 4 groups into a single day 3 group for BAL examinations.

\section{BAL fluid analysis}

The median volume of BAL fluid recovered from lavaged rat lungs was $13.5 \pm 0.5 \mathrm{~mL}$, and no difference was observed between groups and days. All BAL fluids were clear. The total alveolar cell count is shown in Figure 5. A significantly higher total alveolar cell count was observed in the PTX-LNCs spray group compared to the control group on days 1 and 3 . The alveolar differential cell count is described in Table 2. No eosinophil was observed in BAL. An increased proportion of granulocytes (neutrophils) was observed on day 1 in all the groups compared to the control group. The highest proportion of granulocytes was observed in the PTX-LNCs spray group. On day 3, the proportion of granulocytes decreased and the proportion of lymphocytes then increased. On day 7, the proportions of the various cells returned to baseline. Three examples of BAL are shown in Figure 6. Foamy macrophages were observed since day 1 but were no longer seen on day 7. Lipid index was calculated on days 1 and 3 (Figure 7). Examples of foamy macrophages are shown in Figure 8. Total protein assay is illustrated in Figure 9. Results indicate an increase in the total alveolar cells on the PTX-LNCs spray group only at day 1 .

\section{Necropsy and long-term histological examination}

Follow-up of the animals until day 60 did not demonstrate any clinical or behavioral abnormalities. No macroscopic 

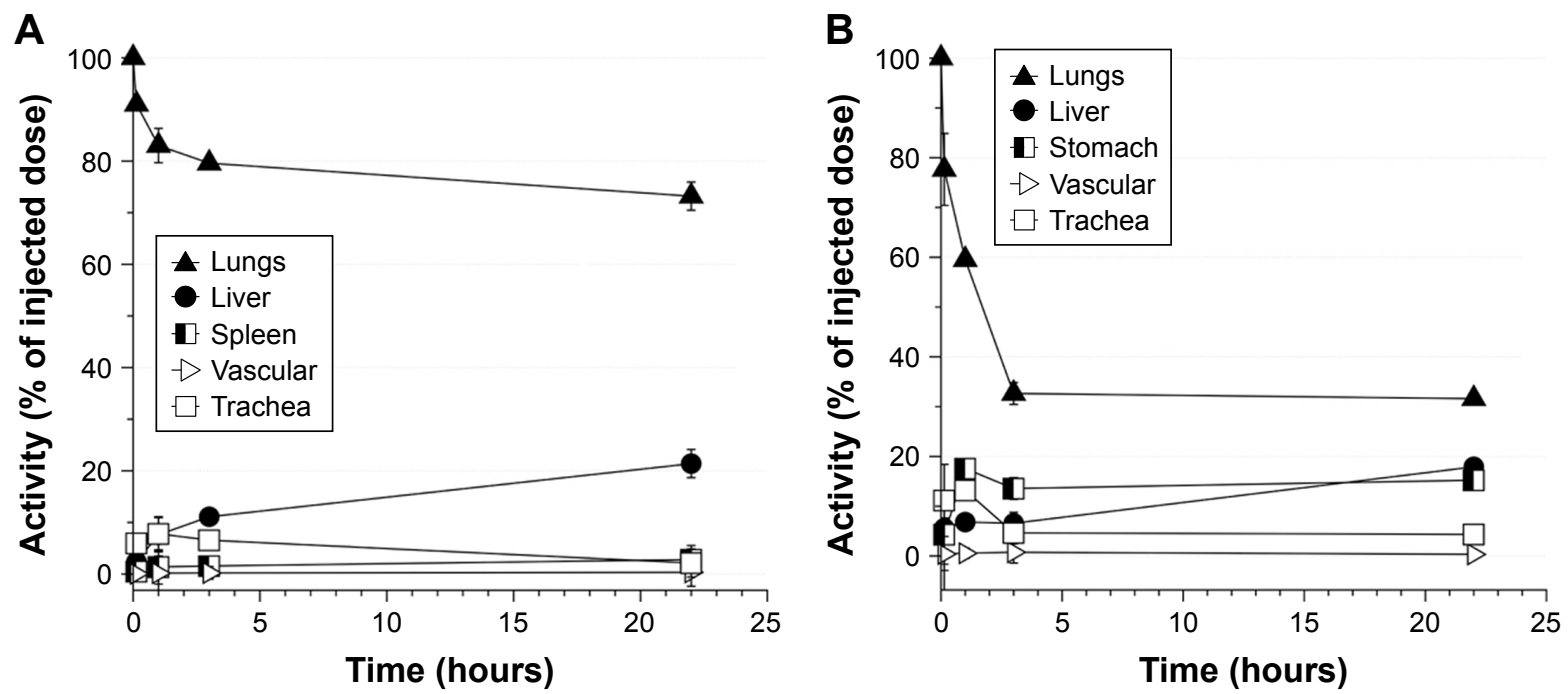

Figure 3 Time-activity curves for LNCs- ${ }^{99 \mathrm{~m}} \mathrm{Tc}$-SSS (A) and ${ }^{99 \mathrm{~m}} \mathrm{Tc}$-pertechnetate control-injected rats (B).

Notes: The error bars are too small to be seen over the time. These curves showed a lung retention of activity with LNCs, whereas there was a faster Cl with the controls. Vascular corresponds to an ROI on the thigh muscle.

Abbreviations: $\mathrm{Cl}$, clearance; LNCs, lipid nanocapsule; ROI, region of interest.

abnormality of the lungs, heart, kidneys, liver, spleen, ovaries or gastrointestinal tract was observed on necropsy examinations. No lymph node hypertrophy or pleural, pericardial or peritoneal effusion was observed. Histological examination of the lungs removed on day 60 did not reveal any signs of pulmonary toxicity according to a previously published histopathological score (Table 3). ${ }^{14}$ Typical pulmonary lesions are shown in Figure 10.

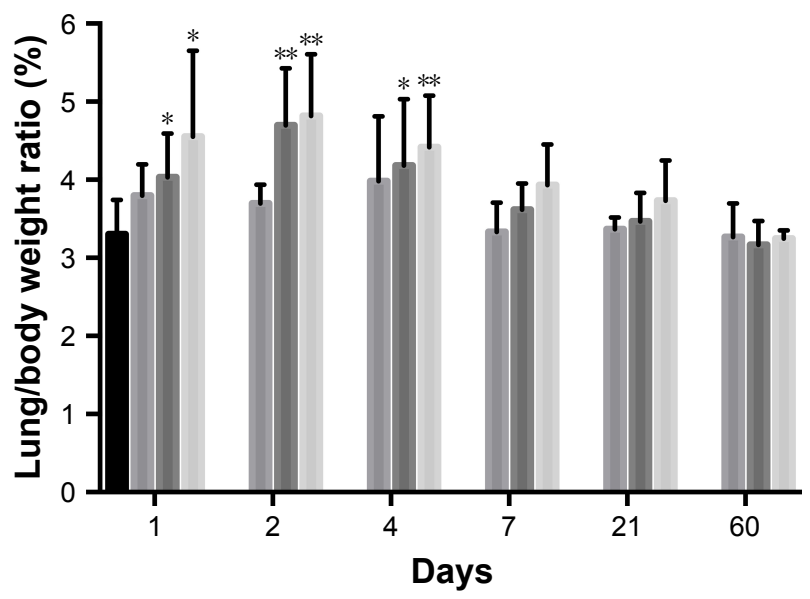

Control group (no spray) Saline serum spray groups Blank LNCs spray groups PTX-LNCs spray groups

Figure 4 Mean \pm SD of lung/body weight ratio for the control group (no spray), the saline serum spray group, the blank LNCs spray group and the PTX-LNCs spray group at days I, 2, 4, 7, 21 and $60(n=6)$.

Notes: Results indicate an increase in the ratio at days I, 2 and 4 in the blank LNCs and PTX-LNCs groups. At days 7, 21 and 60, no difference is observed. ${ }^{*} p<0.05$ versus the control group. ${ }^{* *} p<0.01$ versus the control group.

Abbreviations: LNCs, lipid nanocapsule; PTX, paclitaxel; PTX-LNCs, PTX-loaded LNCs.

\section{Surface tension analysis}

Analysis of alveolar surface tension is shown in Figure 11. The surface tension on the captive bubble was not modified by the addition of saline. The addition of Kolliphor HS15 $(50 \mu \mathrm{g} / \mathrm{mL})$ and Curosurf $(50 \mu \mathrm{g} / \mathrm{mL})$ lowered captive bubble surface tension from about $70.3 \pm 0.4$ to $47.4 \pm 0.5$ and $46.2 \pm 0.4 \mathrm{mN} / \mathrm{m}$ after 360 seconds, respectively. The addition of LNCs, at a concentration equivalent to $50 \mu \mathrm{g} / \mathrm{mL}$ of Kolliphor HS15, lowered captive bubble surface tension

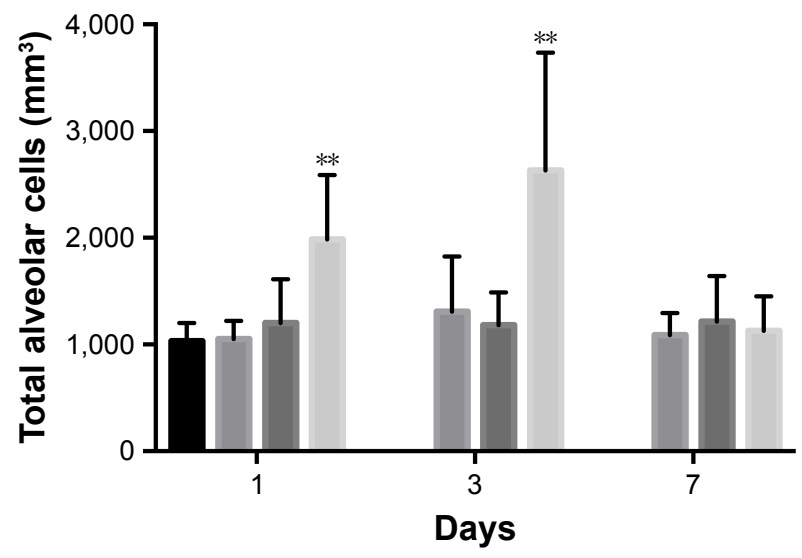

Control group (no spray) Blank LNCs spray groups

Saline serum spray groups PTX-LNCs spray groups

Figure 5 Mean \pm SD of total alveolar cells for the control group (no spray), the saline serum spray group, the blank LNCs spray group and the PTX-LNCs spray group at days I, 3 and $7(n=6)$.

Notes: Results indicate an increase in the total alveolar cells on the PTX-LNCs spray group only at days I and 3 . At day 7 , no difference is observed. ${ }^{*} p<00.01$ versus the control group.

Abbreviations: LNCs, lipid nanocapsule; PTX, paclitaxel; PTX-LNCs, PTX-loaded LNCs. 
Table 2 Macrophage, lymphocyte and granulocyte counts in cells $/ \mathrm{mm}^{3}$ in BAL (percentage in parentheses) in the four groups at days I, 3 and 7

\begin{tabular}{|c|c|c|c|}
\hline Formulation group & Day I & Day 3 & Day 7 \\
\hline \multirow[t]{3}{*}{ Control group (no spray) } & M: $978 \pm I 56(95 \pm I)$ & & \\
\hline & $\mathrm{L}: 5 \mathrm{I} \pm 20(5 \pm \mathrm{I})$ & & \\
\hline & G: $0 \pm 0(0 \pm 0)$ & & \\
\hline \multirow[t]{3}{*}{ Saline serum spray group } & M: $965 \pm I 44(92 \pm 4)$ & M: I,249 $\pm 490(95 \pm 3)$ & M: I,028 $\pm 174(95 \pm 3)$ \\
\hline & L: $29 \pm 26(3 \pm 2)$ & L: $5 \mathrm{I} \pm 5 \mathrm{I}(4 \pm 4)$ & L: $44 \pm 29(4 \pm 2)$ \\
\hline & G: $58 \pm 58(5 \pm 5)^{*}$ & $\mathrm{G}: 9 \pm 9(I \pm I)$ & G: $14 \pm 14(I \pm I)$ \\
\hline \multirow[t]{3}{*}{ Blank LNCs spray group } & M: $8|7 \pm 3| 3(68 \pm 6)$ & M: I,065 $\pm 273(90 \pm 4)$ & M: I, I57 $\pm 403(95 \pm 2)$ \\
\hline & L: $39 \pm 54(3 \pm 3)$ & L: $92 \pm 66(7 \pm 5)$ & L: $54 \pm 30(4 \pm 2)$ \\
\hline & G: $344 \pm$ I I8 (29 \pm 8$)^{* *}$ & G: $25 \pm 25(3 \pm 3)$ & G: $4 \pm 4(I \pm I)$ \\
\hline \multirow[t]{3}{*}{ PTX-LNCs spray group } & $M: 1,164 \pm 176(61 \pm 10)$ & M: $2,296 \pm 955(88 \pm 3)^{* *}$ & M: I,074 \pm 3 II $(95 \pm I)$ \\
\hline & L: $|44 \pm 10|(7 \pm 5)$ & L: $242 \pm 127(9 \pm 3)^{* *}$ & $L: 4 I \pm I 4(4 \pm I)$ \\
\hline & G: $676 \pm 40 \mathrm{I}(32 \pm \mathrm{II})^{* *}$ & G: $91 \pm 48(3 \pm 2)^{* *}$ & G: II $I I I(I \pm I)$ \\
\hline
\end{tabular}

Notes: ${ }^{*} p<0.05$ versus the control group. ${ }^{*} p<0.0$ l versus the control group. Data presented as mean $\pm S D$.

Abbreviations: BAL, bronchoalveolar lavage; G, granulocyte; L, lymphocyte; LNCs, lipid nanocapsule; M, macrophage; PTX, paclitaxel; PTX-LNCs, PTX-loaded LNCs.

from about 70 to $42.0 \pm 0.5 \mathrm{mN} / \mathrm{m}$ after 360 seconds $(p<0.05$ versus Kolliphor HS15 and Curosurf).

\section{Discussion}

In this study, we studied the pulmonary drug delivery of a single endotracheal spray of LNCs or PTX-LNCs in rats. This study compiles data on the in vitro cytotoxicity analysis of LNCs and PTX-LNCs after spray generation by a MicroSprayer Aerosolizer, the biodistribution of LNCs after a spray in rats' lungs, the alveolar toxicity of a single endotracheal spray in rats of LNCs and PTX-NCL and the 60-day toxicity analysis. Exploratory study of the surfactant potential of LNCs on a physicochemical model of the pulmonary alveolus is also described. The results are the absence of structural degradation or loss of cytotoxicity of LNCs and PTX-LNCs after passage in a MicroSprayer Aerosolizer, a predominant biodistribution of LNCs in the lungs of the rats with a lungs' half-life of $8.8 \pm 0.7$ hours, a $\mathrm{Cl}$ of $0.087 \pm 0.007 \mathrm{~h}^{-1}$ after pulmonary delivery, an initial and transient alveolar inflammation reflected by hypercellularity and increased total proteins in BAL fluid and the absence of lung tissue lesions observable under light microscopy 60 days after a single endotracheal dose.

We first confirm previous results concerning the ability of LNCs to remain structurally and functionally unchanged after aerosol generation with the MicroSprayer Aerosolizer. ${ }^{16}$ This procedure has been used in many studies to reproducibly deposit a large volume of solution of interest in the deep lung of rodents. ${ }^{21,30,31}$ The volume of $200 \mu \mathrm{L}$ was chosen, because it corresponds to the maximum volume that can be administered to rats. This procedure was well tolerated and did not cause any death.

Instead of the classical ex vivo studies, a noninvasive approach, based on sequential planar scintigraphic imaging, was preferred to monitor, after endotracheal administration, the ${ }^{99 \mathrm{~m}}$ Tc-LNCs-SSS biodistribution. This method was chosen on the basis of a preliminary unpublished study, which showed that $>90 \%$ of the radiolabeled LNCs remained localized in the lungs after a single spray. In this study, early acquisitions $(\mathrm{t}=10 \mathrm{~min})$ confirmed the good performance of the endotracheal technique for the administration of the LNCs suspensions. Lung deposition appeared to be more effective,

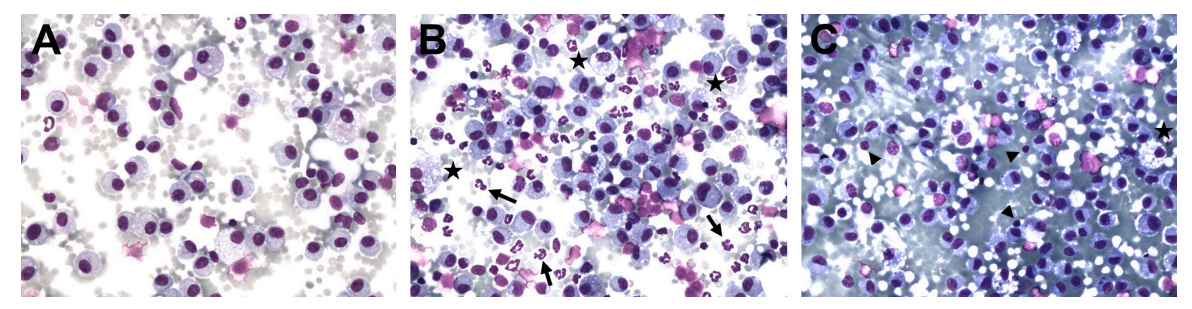

Figure 6 BAL smears after fixation and HES staining (40x).

Notes: (A) Control group rat: the cells are predominantly macrophages. (B) In a rat, 24 hours after PTX-LNCs spray: numerous granulocytes (arrows). All granulocytes were polymorphonuclear neutrophils. (C) In a rat 72 hours after PTX-LNCs spray: marked regression of the granulocyte population and appearance of lymphocytes (arrowheads). Stars indicate foamy macrophages.

Abbreviations: BAL, bronchoalveolar lavage; LNCs, lipid nanocapsule; HES, Hematoxylin-Eosin-Saffron; PTX, paclitaxel; PTX-LNCs, PTX-loaded LNCs. 


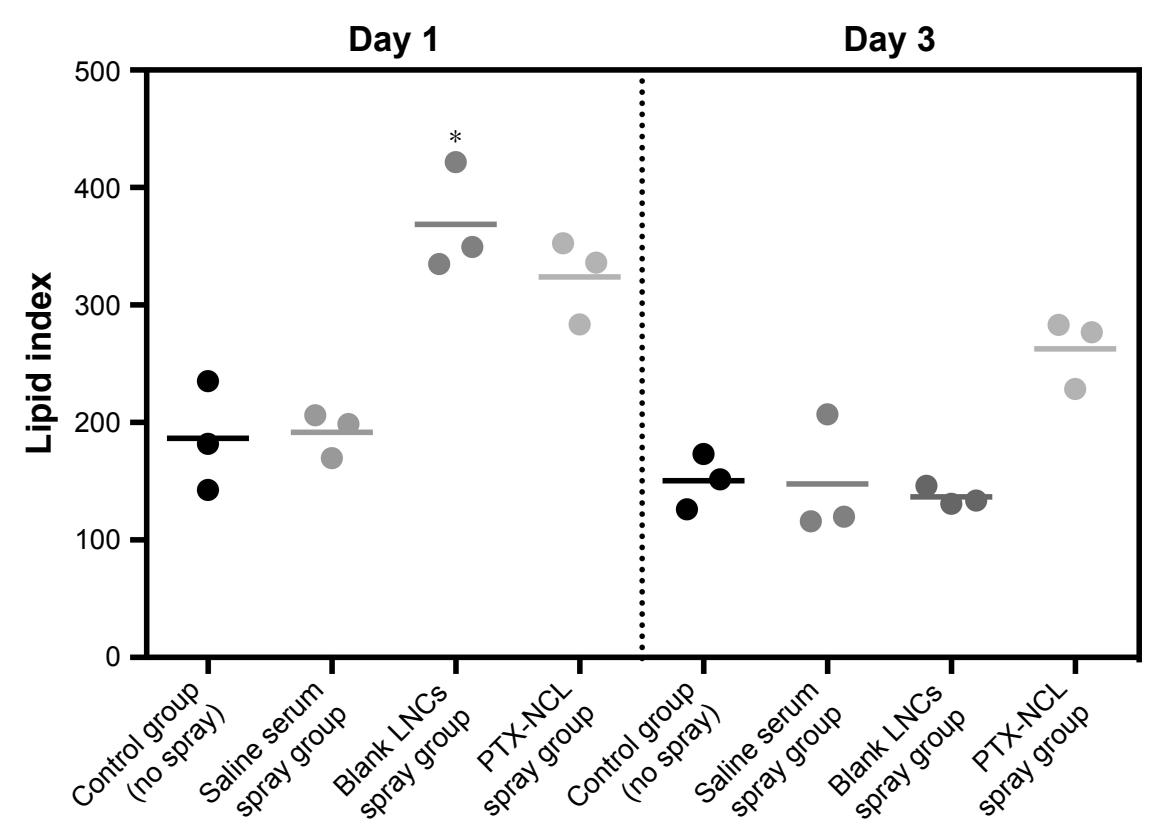

Figure 7 Lipid index in BAL at days $I$ and 3 in the four groups.

Note: ${ }^{*} p=0.05$ versus the saline serum spray group.

Abbreviations: BAL, bronchoalveolar lavage; LNCs, lipid nanocapsule; PTX, paclitaxel; PTX-LNCs, PTX-loaded LNCs.

with far less mouth or throat deposition, as compared to the administration technique by oral aspiration. ${ }^{32}$ The lungs' time-activity curves revealed the slow pulmonary $\mathrm{Cl}$ of LNCs and confirmed the potential value of LNCs to deliver drugs of interest into the deep lung. This slow lung $\mathrm{Cl}$ of radioactivity was not observed with the control animals $(>70 \%$ versus $32 \%$ of the dose is still present in the lung at $\mathrm{t}=22$ hours). Moreover, the discrepancies in organ biodistribution between the ${ }^{99 m}$ Tc-LNCs-SSS and the controls clearly demonstrate the effect of LNCs on the behavior of the drug (ie, ${ }^{99 \mathrm{~m}} \mathrm{Tc}$ ).

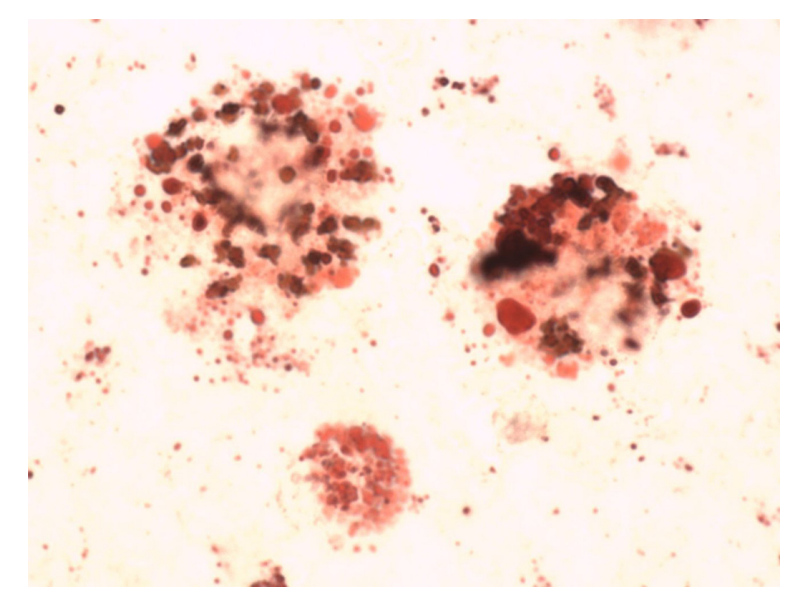

Figure 8 Oil red $O$ staining of three macrophages from BAL at day $I$ in the PTXLNCs spray group (immersion, $\times 100$ ).

Note: Each macrophage was scored at 3.

Abbreviations: BAL, bronchoalveolar lavage; LNCs, lipid nanocapsule; PTX, paclitaxel; PTX-LNCs, PTX-loaded LNCs.
Indeed, after the lung $\mathrm{Cl},{ }^{99} \mathrm{TcO}_{4}^{-}$control animals showed an accumulation of the tracer in the stomach (which is a classic uptake organ for ${ }^{99} \mathrm{TcO}_{4}^{-}$), whereas ${ }^{99 \mathrm{~m}} \mathrm{Tc}-\mathrm{LNCs}-\mathrm{SSS}$ showed only an accumulation in the liver, which indicates that a portion of $\mathrm{LNCs}$ (ie, $21.4 \%$ at $\mathrm{t}=22$ hours) was able to cross the air-blood barrier and reach the systemic circulation before its uptake by mononuclear phagocytic system (MPS) organs such as liver.

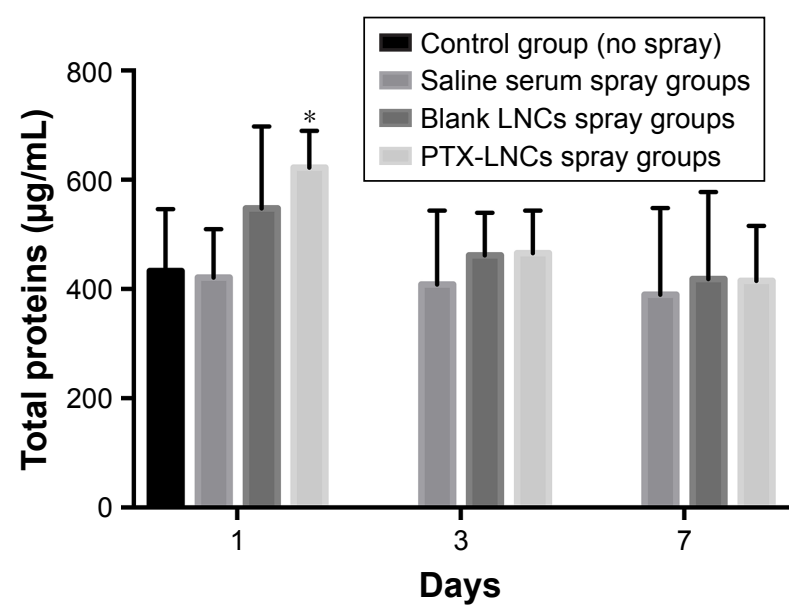

Figure 9 Mean \pm SD of total proteins for the control group (no spray), the saline serum spray group, the blank LNCs spray group and the PTX-LNCs spray group at days I, 3 and $7(n=6)$.

Notes: Results indicate an increase in the total alveolar cells on the PTX-LNCs spray group only at day I. At days 3 and 7 , no difference is observed. $* p<0.05$ versus the control group.

Abbreviations: LNCs, lipid nanocapsule; PTX, paclitaxel; PTX-LNCs, PTX-loaded LNCs. 
Table 3 Histopathological scores by anatomical compartments of the lungs in the three groups at day 60

\begin{tabular}{llllll}
\hline Formulation group & $\begin{array}{l}\text { Peribronchial } \\
\text { compartment }\end{array}$ & $\begin{array}{l}\text { Perivascular } \\
\text { compartment }\end{array}$ & $\begin{array}{l}\text { Interstitial } \\
\text { compartment }\end{array}$ & $\begin{array}{l}\text { Alveolar } \\
\text { compartment }\end{array}$ & $\begin{array}{l}\text { Global } \\
\text { score }\end{array}$ \\
\hline Saline serum spray group & $1.8 \pm 0.4$ & $1.0 \pm 0.0$ & $0.3 \pm 0.8$ & $0.0 \pm 0.0$ & $3.2 \pm 0.4$ \\
Blank LNCs spray group & $1.8 \pm 0.4$ & $1.2 \pm 0.4$ & $0.2 \pm 0.4$ & $0.0 \pm 0.0$ & $3.2 \pm 0.4$ \\
PTX-LNCs spray group & $1.5 \pm 0.5$ & $1.2 \pm 0.4$ & $0.0 \pm 0.0$ & $0.0 \pm 0.0$ & $2.7 \pm 0.5$ \\
Kruskal-Wallis test & NS & NS & NS & NS \\
\hline
\end{tabular}

Notes: No significant difference is observed. Data presented as mean $\pm S D$.

Abbreviations: LNCs, lipid nanocapsule; PTX, paclitaxel; PTX-LNCs, PTX-loaded LNCs; NS, not significant.

The low level of the extrapulmonary distribution should reduce the risk of systemic toxicity. Patel et al ${ }^{32}$ studied this parameter in mice and showed that $50 \mathrm{~nm}$ LNCs administered by oral aspiration were retained by the lungs with a half-life of 10.5 hours (which is consistent with our results) and that moderate pulmonary inflammation did not reduce the pulmonary $\mathrm{Cl}$ of LNCs.

This study mainly focused on the detection of tissue lesions, such as pulmonary fibrosis, 60 days after endotracheal spray of LNCs in rats, as the absence of such lesions provides essential information in terms of preclinical safety. We looked for signs of acute alveolar inflammation by means of three parameters: lung weight/body weight ratio, changes in alveolar cell populations and changes in total alveolar proteins, reflecting tissue edema, cell influx and alveolar injury, respectively. We then performed light microscopy examination of the lungs to determine whether this inflammation resolved without leaving any tissue "sequelae" or whether it progressed to chronic inflammation. We did not study the immunological mechanisms involved in this inflammation (immune cell populations, cytokines and interleukin networks). This study is important, as particles with a large surface area/mass ratio can induce local toxicity via tissue inflammation, which can then induce tissue fibrosis. Jones et $\mathrm{al}^{16}$ published the first toxicity study after pulmonary administration of $25 \mu \mathrm{L}$ of $50 \mathrm{~nm}$ LNCs at a dose of 0.8 or $8 \mathrm{mg} / \mathrm{mL}$ per lung in mice. This study showed no changes in alveolar cell populations and an increase in total alveolar

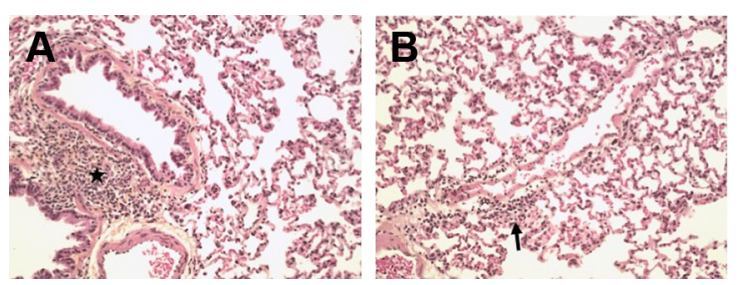

Figure 10 Light microscopy histological examination of the lungs on day 60 after fixation and HES staining (20X).

Notes: (A) Example of perivascular nodule of mononuclear leukocytes (star). (B) Example of a peribronchiolar nodule of mononuclear leukocytes (arrow).

Abbreviation: HES, Hematoxylin-Eosin-Saffron. proteins at the highest dose 24 hours after endotracheal spray delivered by a MicroSprayer Aerosolizer. Unlike Jones et al, we observed signs of alveolar inflammation, and this difference can be explained by the choice of the dose administered and the choice of animal species. We used undiluted LNCs and PTX-LNCs formulations, corresponding to a more than 10-fold higher surface area dose than the highest concentration used by Jones et al. ${ }^{16}$ This concentration difference could explain the absence of toxicity in the study by Jones et al and the presence of toxicity in our study. We chose such a high concentration, because highly concentrated solutions allow the use of small nebulization volumes, resulting in shorter nebulization times for the patient. We have shown that the only commercial apparatus able to nebulize LNCs is the eFlow ${ }^{\circledR}$ rapid. $^{4}$ This apparatus has a $3 \mathrm{~mL}$ reservoir and takes 8.4 minutes to nebulize the volume of LNCs used in this study. We believe that the concentrations used in the studies by Jones et al were too low compared to the doses of

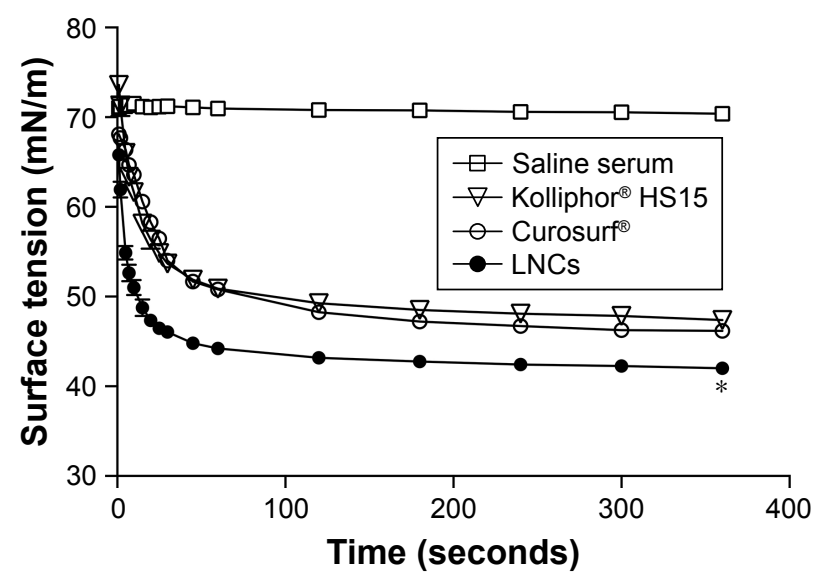

Figure I I Evolution of surface tension on the captive bubble versus time after the addition of saline serum, $50 \mu \mathrm{g} / \mathrm{mL}$ of Curosurf ${ }^{\circledR}, 50 \mu \mathrm{g} / \mathrm{mL}$ of Kolliphor $^{\circledR} \mathrm{HSI} 5$ and LNCs at a concentration equivalent to $50 \mu \mathrm{g} / \mathrm{mL}$ Kolliphor HSI 5 .

Notes: Isotherms were obtained by monitoring adsorption of the mixtures in the captive bubble tensiometer at $37^{\circ} \mathrm{C}$. Data are mean \pm SD of three independent experiments. The error bars are too small to be seen over the time. ${ }^{*} p<0.05$ versus the Kolliphor HSI 5 and Curosurf. This figure illustrates the greater capacity of LNCs to reduce the surface tension on the captive bubble than Curosurf and Kolliphor HSI 5 alone.

Abbreviation: LNCs, lipid nanocapsule. 
LNCs required in aerosol therapy. Furthermore, in contrast to Jones et al who took mice, our studies were conducted in rats, as the Organization for Economic Cooperation and Development recommends conducting acute lung toxicity studies in 8-12-week-old rats that have been acclimatized for at least 5 days. ${ }^{33}$ Rats appear to be more sensitive than mice or hamsters to the risk of pulmonary fibrosis. ${ }^{34}$ Our decision to perform this study in rats was therefore well adapted to the objective of this study.

In this study, we minimized the causes of exogenous pulmonary inflammation. We removed the excess of Kolliphor HS15 stabilizer by $0.22 \mu \mathrm{m}$ filtration, which also allowed sterilization of the final LNCs and PTX-LNCs solutions before storage. Sterile normal saline was also used. We have previously demonstrated the pyrogen-free nature of the LNCs formulation. ${ }^{4}$ Despite these precautions, it is noteworthy that simple endotracheal spray of normal saline induced a transient alveolar inflammatory reaction on day 1 in the rats of the saline serum group. The results of this study appear to justify the initiation of chronic toxicity studies in rats, which must look for the presence of chronic inflammation, pulmonary fibrosis and lipid accumulation. We did not investigate possible accumulation of lipids in the lungs, as lipid accumulation requires chronic exposure to inhaled lipids. We observed a higher proportion of foamy macrophages in the blank LNCs and PTX-LNCs groups than in the control and saline serum spray groups on day 1 . The proportion of foamy macrophages then decreased on day 3 , and they were no longer visible on day 7 . These findings demonstrated progressive elimination of part of the lipids delivered in the aerosol by alveolar macrophages over the 7 days following endotracheal spray. Furthermore, Patel et $\mathrm{al}^{32}$ showed that the alveolar inflammation induced by LNCs did not modify the pulmonary $\mathrm{Cl}$ of these particles in mice, and therefore did not increase the risk of accumulation of the components of LNCs, particularly lipids, following the administration of a single dose.

Finally, we confirm that LNCs have surfactant property. ${ }^{35}$ We demonstrated that this property was more effective than the tensio-active component alone of the LNCs (Kolliphor HS15) and the commercial animal-derived surfactant Curosurf.

\section{Conclusion}

A single pulmonary delivery of blank LNCs or PTX-LNCs induces a short-term alveolar inflammation with no residual lesions in rats at day 60. These results indicate that LNCs is a potential drug carrier for pulmonary delivery of PTX.

\section{Acknowledgments}

This work was performed with the financial support of the Institut Régional en Santé Respiratoire dans les Pays de la Loire (rue du Landreau, Beaucouzé, France), the Comité départemental du Maine-et-Loire et de Charente, Cancéropôle Grand Ouest and the Bretagne, Centre, Pays de la Loire and Poitou-Charentes Régions. This study was performed with the technical assistance of Mr P Legras and Mr J Roux of the Angers University Hospital animal facility and Mrs A Godefroy.

\section{Disclosure}

The authors report no conflicts of interest in this work.

\section{References}

1. Heurtault B, Saulnier P, Pech B, Proust JE, Benoit JP. A novel phase inversion-based process for the preparation of lipid nanocarriers. Pharm Res. 2002;19(6):875-880.

2. Koshkina NV, Waldrep JC, Roberts LE, Golunski E, Melton S, Knight V. Paclitaxel liposome aerosol treatment induces inhibition of pulmonary metastases in murine renal carcinoma model. Clin Cancer Res. 2001;7(10):3258-3262

3. Umerska A, Mouzouvi CR, Bigot A, Saulnier P. Formulation and nebulization of fluticasone propionate-loaded lipid nanocarriers. Int $J$ Pharm. 2015;493(1-2):224-232.

4. Hureaux J, Lagarce F, Gagnadoux F, et al. Lipid nanocapsules: readyto-use nanovectors for the aerosol delivery of paclitaxel. Eur J Pharm Biopharm. 2009;73(2):239-246.

5. Lahzami S, King GG. Targeting small airways in asthma: the new challenge of inhaled corticosteroid treatment. Eur Respir J. 2008;31(6): $1145-1147$.

6. Boe J, Dennis JH, O’Driscoll BR, et al; European Respiratory Society Task Force on the use of nebulizers. European Respiratory Society Guidelines on the use of nebulizers. Eur Respir J. 2001;18(1): 228-242.

7. Rubin BK. Aerosol medications for treatment of mucus clearance disorders. Respir Care. 2015;60(6):825-829; discussion 830-832.

8. Jobe AH. Pulmonary surfactant therapy. N Engl J Med. 1993;328(12): 861-868.

9. Gagnadoux F, Hureaux J, Vecellio L, et al. Aerosolized chemotherapy. J Aerosol Med Pulm Drug Deliv. 2008;21(1):61-70.

10. Blottière HM, de Vos WM, Ehrlich SD, Doré J. Human intestinal metagenomics: state of the art and future. Curr Opin Microbiol. 2013;16(3): 232-239.

11. Wang M, Monaco MH, Donovan SM. Impact of early gut microbiota on immune and metabolic development and function. Semin Fetal Neonatal Med. 2016;21(6):380-387.

12. Diaz Heijtz R. Fetal, neonatal, and infant microbiome: perturbations and subsequent effects on brain development and behavior. Semin Fetal Neonatal Med. 2016;21(6):410-417.

13. Cong X, Xu W, Romisher R, et al. Gut microbiome and infant health: brain-gut-microbiota axis and host genetic factors. Yale J Biol Med. 2016;89(3):299-308.

14. Hureaux J, Lagarce F, Gagnadoux F, et al. Toxicological study and efficacy of blank and paclitaxel-loaded lipid nanocapsules after i.v. administration in mice. Pharm Res. 2010;27(3):421-430.

15. Hureaux J, Lagarce F, Gagnadoux F, Clavreul A, Benoit JP, Urban T. The adaptation of lipid nanocapsule formulations for blood administration in animals. Int J Pharm. 2009;379(2):266-269.

16. Jones MC, Jones SA, Riffo-Vasquez Y, et al. Quantitative assessment of nanoparticle surface hydrophobicity and its influence on pulmonary biocompatibility. J Control Release. 2014;183:94-104. 
17. Dailey LA, Hernandez-Prieto R, Casas-Ferreira AM, et al. Adenosine monophosphate is elevated in the bronchoalveolar lavage fluid of mice with acute respiratory toxicity induced by nanoparticles with high surface hydrophobicity. Nanotoxicology. 2015;9(1):106-115.

18. Grabowski N, Hillaireau H, Vergnaud J, et al. Toxicity of surfacemodified PLGA nanoparticles toward lung alveolar epithelial cells. Int J Pharm. 2013;454(2):686-694.

19. Thomas O, Lagarce F. Lipid nanocapsules: a nanocarrier suitable for scale-up process. J Drug Deliv Sci Technol. 2013;23(6):555-559.

20. Lepareur N, Noiret N, Henry JY. A kit formulation for the labelling of lipiodol with generator-produced 188Re. J Labelled Comp Radiopharm. 2004;47(12):857-867.

21. Gagnadoux F, Le Pape A, Urban T, et al. Safety of pulmonary administration of gemcitabine in rats. J Aerosol Med. 2005;18(2):198-206.

22. Cory AH, Owen TC, Barltrop JA, Cory JG. Use of an aqueous soluble tetrazolium/formazan assay for cell growth assays in culture. Cancer Commun. 1991;3(7):207-212.

23. Riss TL, Moravec RA. Comparison of MTT, XTT, and a novel tetrazolium compound for MTS for in vitro proliferation and chemosensitivity assays. Mol Biol Cell. 1992;3(Suppl):184A.

24. Parker JC, Townsley MI. Evaluation of lung injury in rats and mice. Am J Physiol Lung Cell Mol Physiol. 2004;286(2):L231-L246.

25. Hopkins PM, Kermeen F, Duhig E, et al. Oil red O stain of alveolar macrophages is an effective screening test for gastroesophageal reflux disease in lung transplant recipients. J Heart Lung Transplant. 2010; 29(8):859-864.

26. Schurch S, Green FH, Bachofen H. Formation and structure of surface films: captive bubble surfactometry. Biochim Biophys Acta. 1998; 1408(2-3):180-202.
27. Saulnier P, Foussard F, Boury F, Proust JE. Structural properties of asymmetric mixed-chain phosphatidylethanolamine films. J Colloid Interface Sci. 1999;218(1):40-46.

28. Minkov I, Ivanova T, Panaiotov I, Proust J, Saulnier P. Reorganization of lipid nanocapsules at air-water interface. I. Kinetics of surface film formation. Colloids Surf B Biointerfaces. 2005;45(1):14-23.

29. Yamori T, Sato S, Chikazawa H, Kadota T. Anti-tumor efficacy of paclitaxel against human lung cancer xenografts. Jpn J Cancer Res. 1997; 88(12):1205-1210.

30. Montharu J, Le Guellec S, Kittel B, et al. Evaluation of lung tolerance of ethanol, propylene glycol, and sorbitan monooleate as solvents in medical aerosols. J Aerosol Med Pulm Drug Deliv. 2010;23(1): 41-46.

31. Gutbier B, Kube SM, Reppe K, et al. RNAi-mediated suppression of constitutive pulmonary gene expression by small interfering RNA in mice. Pulm Pharmacol Ther. 2010;23(4):334-344.

32. Patel A, Woods A, Riffo-Vasquez Y, et al. Lung inflammation does not affect the clearance kinetics of lipid nanocapsules following pulmonary administration. J Control Release. 2016;235:24-33.

33. OECD. Test No. 436: Acute Inhalation Toxicity - Acute Toxic Class Method. Paris, France: OECD Publishing; 2009.

34. Bermudez E, Mangum JB, Asgharian B, et al. Long-term pulmonary responses of three laboratory rodent species to subchronic inhalation of pigmentary titanium dioxide particles. Toxicol Sci. 2002;70(1): 86-97.

35. Umerska A, Cassisa V, Matougui N, Joly-Guillou ML, Eveillard M, Saulnier P. Antibacterial action of lipid nanocapsules containing fatty acids or monoglycerides as co-surfactants. Eur J Pharm Biopharm. 2016;108:100-110.
International Journal of Nanomedicine

\section{Publish your work in this journal}

The International Journal of Nanomedicine is an international, peerreviewed journal focusing on the application of nanotechnology in diagnostics, therapeutics, and drug delivery systems throughout the biomedical field. This journal is indexed on PubMed Central, MedLine, CAS, SciSearch ${ }^{\circledR}$, Current Contents ${ }^{\circledR} /$ Clinical Medicine,

\section{Dovepress}

Journal Citation Reports/Science Edition, EMBase, Scopus and the Elsevier Bibliographic databases. The manuscript management system is completely online and includes a very quick and fair peer-review system, which is all easy to use. Visit http://www.dovepress.com/ testimonials.php to read real quotes from published authors. 